\title{
Earmarked paternity leave and the relative income within couples
}

Druedahl, Jeppe; Ejrnæs, Mette; Jørgensen, Thomas Høgholm

Published in:

Economics Letters

DOI:

10.1016/j.econlet.2019.04.018

Publication date:

2019

Document version

Early version, also known as pre-print

Citation for published version (APA):

Druedahl, J., Ejrnæs, M., \& Jørgensen, T. H. (2019). Earmarked paternity leave and the relative income within couples. Economics Letters, 180, 85-88. https://doi.org/10.1016/j.econlet.2019.04.018 
C E N T E R F OR

E C O N O M I C

B E H A V I O R \&

CEBI WORKING PAPER SERIES

I N E Q U A L I T Y

Working Paper 02/19

EARMARKED PATERNITY LEAVE AND THE RELATIVE INCOME WITHIN COUPLES

Jeppe Druedahl

Mette Ejrnæs

Thomas H. Jørgensen

ISSN 2596-44TX

\section{CEBI}

Department of Economics University of Copenhagen www.cebi.ku.dk 


\title{
Earmarked Paternity Leave and the Relative Income within Couples*
}

\author{
Jeppe Druedahl ${ }^{\dagger}$ \\ Mette Ejrnæs ${ }^{\ddagger}$ \\ Thomas H. Jørgensen ${ }^{\S}$
}

April 10, 2019

\begin{abstract}
We study the causal link between earmarked paternity leave policies and the relative income share of women within couples. We utilize high quality administrative longitudinal register data for the universe of Danish individuals with a reform in 1998, which increased the earmarked paternity leave of fathers from two to four weeks. We estimate that the reform increased the women's intra-household share of labor income with around 1.2 percentage points in the years following childbirth. We estimate a significant increase up to seven years after childbirth. We furthermore find that the effect is primarily driven by women employed in the private sector. (JEL: D63, H24, H31, J13, J16, J24, J78)
\end{abstract}

Keywords: Income Share, Parental Leave, Earmarked Leave, Household Bargaining.

\footnotetext{
*We thank seminar participants at CEBI. Joachim Kahr Rasmussen provided excellent research assistance. Financial support from the Economic Policy Research Network (EPRN) and the Danish Council for Independent Research in Social Sciences is gratefully acknowledged (FSE, grant no. 4091-00040 and 5052-00086B). Center for Economic Behavior and Inequality (CEBI) is a center of excellence at the University of Copenhagen, founded in September 2017, financed by a grant from the Danish National Research Foundation. All errors are ours.

${ }^{\dagger}$ CEBI, Department of Economics, University of Copenhagen, Øster Farimagsgade 5, Building 26, DK-1353 Copenhagen K, Denmark. E-mail: jeppe.druedahl@econ.ku.dk. Website: http://econ.ku . $\mathrm{dk} /$ druedahl.

${ }^{\ddagger}$ CEBI, Department of Economics, University of Copenhagen, Øster Farimagsgade 5, building 26, DK-1353 Copenhagen. Contact: mette.ejrnes@econ.ku.dk.

${ }^{\S} \mathrm{CEBI}$, Department of Economics, University of Copenhagen. E-mail: tjo@econ.ku.dk. Website: www. tjeconomics. com.
} 


\section{Introduction}

Reducing gender inequality has become a central motivation for labor market and child care policy reforms. Recently, the European Parliament proposed to impose on member countries that each parent must have the right to two months of non-transferable paid parental leave. ${ }^{1}$ One of the main arguments for this EU-wide legislation was to lower gender inequality by reducing the flexibility of couples to allocate paid parental leave within the households.

While the child-penalty of women has been found to be the single most important driver of the difference in the average income of men and women (Kleven, Landais and Søgaard, forthcoming), relatively little is known about the effects of earmarked parental leave on the relative income of women within couples. ${ }^{2}$ The intra-household income share likely reflects bargaining power (see Browning, Bourguignon, Chiappori and Lechene, 1994) and shifting the income share (and not only levels) thus has the potential to create permanent shifts in norms and gender inequality. In this study, we intent to fill this gap by focusing on women's income share within couples around childbirth.

We estimate the causal effect of increasing the earmarked paternity leave of fathers on the relative labor income of women within the couple. We exploit Danish longitudinal administrative register data together with a reform of the Danish parental leave system implemented in 1998 that provided fathers with two additional earmarked weeks of leave. This reform significantly increased the share of fathers taking at least four weeks of parental leave and led to an increase in women's labor income share of around 1.5 percentage points in the two first years after childbirth. The effect declines over time and remains significant until eight years after birth. We find that the effect is primarily driven by couples in which the woman was employed in the private sector prior to childbirth.

\section{Danish Institutional Setting and Data}

\subsection{Maternity and Paternity Leave Rules and the 1998 Reform}

Before the 1998 reform, the mother was entitled to the first 14 weeks of non-transferable maternity leave after the child was born. The father had two non-transferable leave weeks which should be held within the first 14 weeks of childbirth. Most fathers took (and take) the two weeks immediately after childbirth. Following the first 14 weeks after childbirth reserved for the mother, the couple had the right to 10 weeks transferable benefits.

\footnotetext{
1 The European Parliament is in the process of approving the "Proposal for a directive of the European Parliament and of the Council on work-life balance for parents and carers", proposed in 2017.

2 Existing studies include Duvander, Lappegård and Andersson, 2010; Ekberg, Eriksson and Friebel, 2013; Farre and Gonzalez, 2017; Tamm, 2018; and Avdic and Karimi, 2018.
} 
During these weeks of leave, mothers and fathers received either their salary or parental leave benefits, which is comparable to unemployment benefit. ${ }^{3}$ Furthermore, after the first 24 weeks, the parents could take additionally 26 weeks of transferable care leave. The benefit level of care leave was 60 percent of the unemployment benefit.

In April 1998, a change in the parental leave system was implemented. ${ }^{4}$ All fathers of children born after October 15, 1997 was now entitled to two additional earmarked weeks of paternity leave. These extra weeks had to be taken in weeks 25 and 26 after childbirth. All remaining features of the leave system were unchanged (see Figure A3 in the Supplemental Material). We refer to this as the 1998 reform throughout although it also affected parents of children born in the last one and a half month of 1997.

\subsection{The Data and Sample Selection}

We use linked longitudinal administrative Danish register data on the universe of individuals in Denmark from 1980 to 2013. We restrict attention to women aged 20 to 60 who give birth to their first child during 1995 through $2001 .{ }^{5}$ We require that the woman was either married or cohabiting at the time of birth and refer to the partner as the birth-partner throughout. We restrict attention to opposite-sex couples with at most 15 years of age difference. We only use information in years in which the woman is registered as partner with the birth-partner and we drop years in which either household member is registered as predominantly studying, outside the labor market or have negative labor income. We focus on the period between 3 years prior to first birth and 8 years after first birth. These sample selection criteria yields an unbalanced panel of 161,341 couples and $1,509,986$ observations. ${ }^{6}$

Our primary variable is the share of household labor income earned by the woman. ${ }^{7}$ This variable is based on the total annual labor income for each household member. We also use the number of days of leave of the mother and the father. These variables are defined as the sum of maternity leave, parental leave and childcare leave. ${ }^{8}$

In Table A1 in the Supplemental Material, we present summary statistics of our main

3 Whether the employee received his or her normal salary or the parental leave benefit depended on the employment contract.

4 The law was proposed December 3, 1997, passed December 19, 1997 and were effectuated from April 1, 1998 with retroactive effect for parents of children born from (including) October 15, 1997.

5 The maternity leave system was subject to reforms in 1994 and 2002 and we thus focus on the this narrow window around the 1998 reform.

6 The sample contains about 75 percent of all first born in the relevant cohorts.

7 The measure is based on the "Erhvervsindk 13" variable from Statistics Denmark.

8 The leave variables are constructed from the SHSS register, which contains information on the number of days leave and the annual amount of benefits received at the individual level. Note, that the mother is entitled to go on leave around 4-8 weeks prior to the birth (depending on the type of job and period). 
variables around the year of birth of the firstborn child. The table shows that women's labor income share drops from around 42 percent to around 32 percent at childbirth. The share gradually increases to around 39 percent after eight years.

\subsection{Descriptive Analysis}

Figure 1: Paternity Leave and Relative Incomes around the 1998 Reform.

(a) 4+ Weeks of Paternity Leave.

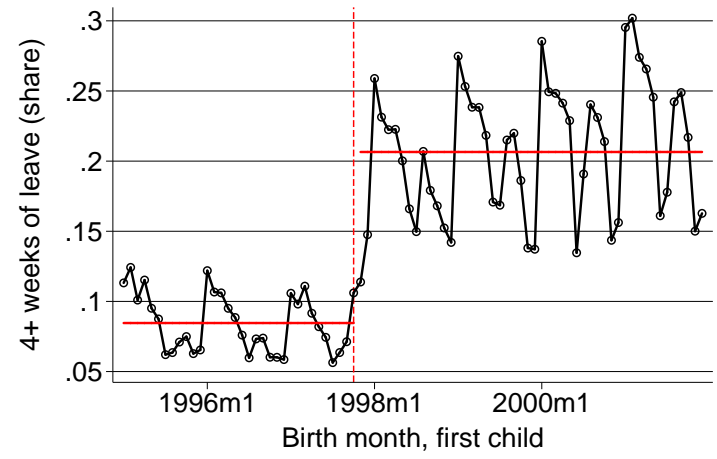

(b) Women's Income Share.

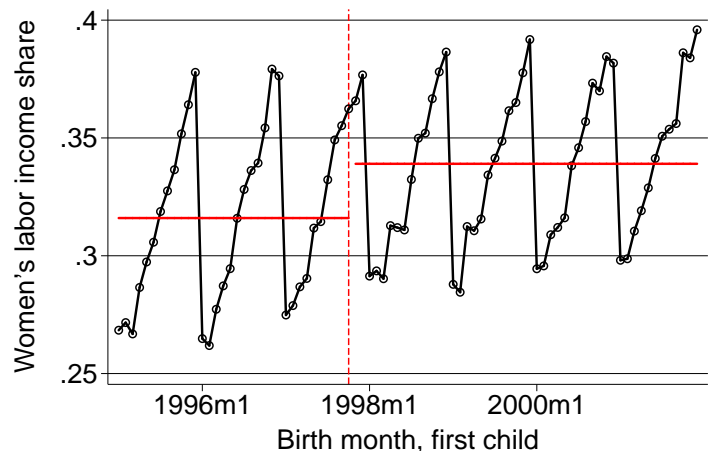

Notes: The figure illustrates in the left panel the share of fathers taking 4 or more weeks of paternity leave across the birth-month of their first child. The right panel similarly illustrates the average labor income share of women across the birth-month of their first child. The dashed vertical line marks the cut-off date October 15, 1997 in paternity leave rules implemented in the 1998 reform. The horizontal straight lines show averages split by whether the first child was born before or after the cut-off date.

Figure 1a shows the share of first-time fathers taking at least 4 weeks of paternity leave as a function of the birth-month of their first child. Here, we see a sharp increase in the share taking at least 4 weeks leave around the cut-off date October 15, 1997 supporting the notion that the increase in the share taking at least 4 weeks of leave is driven by the 1998-reform. All of this increase seems to come from a reduction in the share of fathers taking 2 weeks of leave (Figure A1 in the Supplemental Material). We also see a strong seasonal pattern where the amount of leave taken in the birth-year falls with the birth-month of the child. This is because we measure here the amount of leave taken in the year of birth and children born later in the year will then give a shorter time to realize the paternity leave.

In Figure 1b, we graphically examine the impact of the reform on the women's share of annual labor income within the household in the year the child is born. ${ }^{9}$ The graph shows a strong seasonal pattern, which is driven by the fact that annual income is highly influenced by the month of birth. If a woman gives birth in January, her and her partner's annual income will potentially be affected by the childbirth in all 12 months. For those

9 We use annual variables because that is how the labor income and the received parental leave benefits are available from Statistics Denmark. 
couples, the income share is on average between 27-30 percent. If a woman gives birth in December, her and her partner's annual income will only be affected by the child birth in one month that year, and the income share for those couples is on average around 37 percent in the year of childbirth. Therefore, we will expect the biggest impact of the 1998 reform, when comparing the income shares for those giving birth in the beginning of the calendar year and the lowest effect for those giving birth in end of a calendar year. The figure indicates, in line with this reasoning, that the reform had a positive impact on the labor income share of women in the year the child is born (especially for those giving birth in the beginning of the year). We report a similar plot for number of childbirths in Figure A2 in the supplemental material. The number of births in each month is between 1500-2000.

\section{Causal Estimation Results}

Our baseline empirical strategy is a difference-in-difference (DiD) strategy. In particular, we will identify the effect of the 1998 reform by comparing the change in the labor income share around childbirth of women who had their first child within one year before the reform with those who had their first child within one year after the reform. The latter group is the treatment group having a child after the reform was implemented and the former is the control group. Formally, letting $y_{i, t}$ denote woman's labor income share, at time $t$, we estimate equations of the form,

$$
y_{i, t}=\theta T_{i, t}+\sum_{j=-3}^{8} \gamma_{j} \mathbf{1}\left(\text { YearsSinceFirstBirth } h_{i, t}=j\right)+X_{i, t} \beta+\alpha_{i}+\lambda_{t}+\varepsilon_{i, t}
$$

where the treatment $T_{i, t}=$ FirstChildAfter 1998 Reform $_{i, t} \cdot \mathbf{1}$ (YearsSinceFirstBirth ${ }_{i, t} \geq$ 0 ) equals one when a child born after the reform is present in the household and is zero otherwise. $\theta$ is the DiD estimate of the causal effect of the reform. We include yearssince birth dummies, $\gamma_{j}$ for $j=-3, \ldots, 8$, household-specific fixed effects, $\alpha_{i}$, and yeardummies. ${ }^{10}$ Furthermore, because we found substantial seasonality in the labor income share above, we include a set of birth-month dummies in the year of birth and another set of birth-month dummies in the year after childbirth.

Our estimation results are reported in column (1) of Table 1. We estimate that the reform significantly increased the women's labor income share by around 1.2 percentage points. We also estimate a dynamic version of the model where we interact the treatment effect with dummies for years since birth. Figure 2 shows that the effect of the reform is strongest the first years after child birth and eight years after birth there is no significant

\footnotetext{
${ }^{10}$ We normalize $\gamma_{-1}=0$
} 
Table 1: Decreasing Earmarked Paternity Leave.

\begin{tabular}{|c|c|c|c|c|c|}
\hline & \multirow[b]{2}{*}{ All } & \multicolumn{2}{|c|}{ Woman's sector } & \multicolumn{2}{|c|}{ Man's sector } \\
\hline & & Public & Private & Public & Private \\
\hline & $(1)$ & $(2)$ & $(3)$ & $(4)$ & $(5)$ \\
\hline Treatment & $\begin{array}{c}0.012^{* * *} \\
(0.001)\end{array}$ & $\begin{array}{l}0.005^{*} \\
(0.002)\end{array}$ & $\begin{array}{l}0.018^{* * *} \\
(0.002)\end{array}$ & $\begin{array}{c}0.020 * * * \\
(0.004)\end{array}$ & $\begin{array}{l}0.011^{* * *} \\
(0.001)\end{array}$ \\
\hline Constant & $\begin{array}{c}0.408^{* * * *} \\
(0.001)\end{array}$ & $\begin{array}{c}0.409^{* * *} \\
(0.001)\end{array}$ & $\begin{array}{c}0.425^{* * *} \\
(0.001)\end{array}$ & $\begin{array}{c}0.446^{* * * *} \\
(0.001)\end{array}$ & $\begin{array}{c}0.401^{* * *} \\
(0.001)\end{array}$ \\
\hline Year since birth dummies & Yes & Yes & Yes & Yes & Yes \\
\hline Birth month dummies & Yes & Yes & Yes & Yes & Yes \\
\hline Year dummies & Yes & Yes & Yes & Yes & Yes \\
\hline Household dummies & Yes & Yes & Yes & Yes & Yes \\
\hline $\begin{array}{l}\text { Test for no difference, F-stat. } \\
\text { Test for no difference, p-val. }\end{array}$ & & \multicolumn{2}{|c|}{20.868} & \multicolumn{2}{|c|}{5.081} \\
\hline Obs. & $1,509,986$ & 537,589 & 869,247 & 234,733 & $1,062,708$ \\
\hline Households & 161,341 & 55,505 & 90,587 & 23,965 & 106,667 \\
\hline$R^{2}$ & 0.049 & 0.032 & 0.071 & 0.047 & 0.052 \\
\hline
\end{tabular}

Notes: The table reports estimation results of equation (1) split by each household member's sector of employment one year prior to the first childbirth. Robust standard errors reported in brackets. ${ }^{*} \mathrm{p}<0.05 ;{ }^{* *} \mathrm{p}<0.01 ;{ }^{* * *} \mathrm{p}<0.001$

effect of the reform.

The identifying assumption is that it is random which couples have children just before or after the 1998 reform conditional on the included dummies. The fact that fathers who had their first child up to 24 weeks before the law was implemented were entitled to the additional earmarked weeks, makes it more plausible that the assumption holds. To investigate our design, we also performed a placebo test where we imagine an artificial reform implemented in 2004 affecting couples who gave birth after October 15, 2003. We then perform the same analysis on couples who gave birth between January 1, 2002 through 2006. ${ }^{11}$ Reassuringly, the placebo test reported in Table A2 in the Supplemental Material shows no effect.

\footnotetext{
${ }^{11}$ The year for the placebo reform is chosen because there was another reform in 2002 .
} 
Figure 2: Dynamic Response.

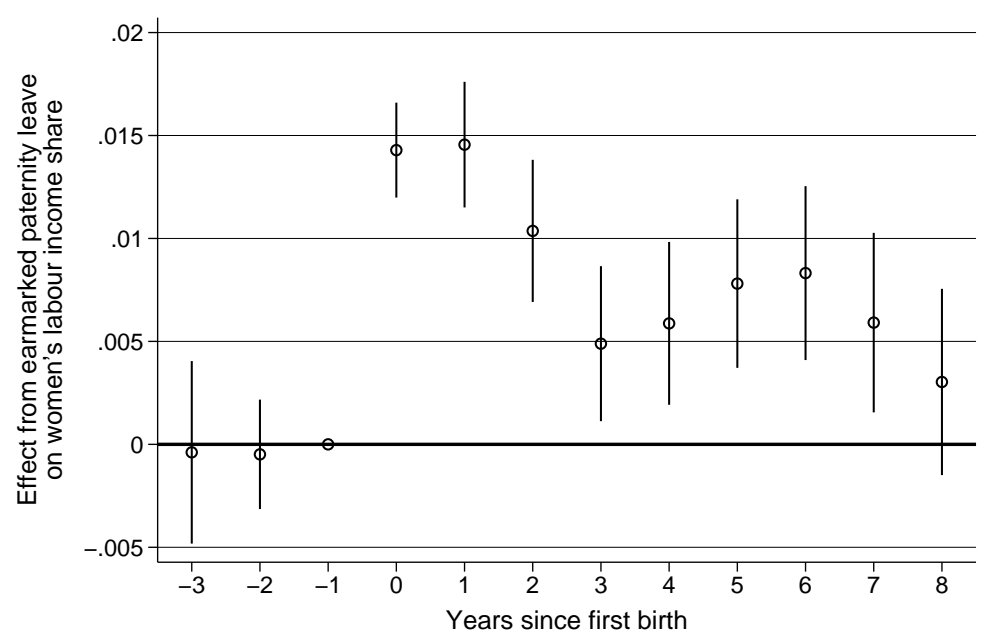

Notes: The figure illustrates estimated coefficients of the treatment effect interacted with years since birth. Circles are point estimates and vertical lines illustrate $95 \%$ confidence intervals based on robust standard errors. In the estimation is included a full set of year-since-birth, birth month, year, and household dummies.

\subsection{Heterogeneity}

Columns (2)-(4) of Table 1 reports estimated treatment effects for four sub-samples based on whether the woman or the man worked in the public or private sector one year prior to childbirth. We see that the effect is significantly larger for women employed in the private sector compared to women employed in the public sector and slightly lower (and insignificant) for women with partners employed in the public sector. To understand these results, note that the percentage increase in the share of fathers taking at least 4 weeks of leave was thus twice as large for the group of women employed in the private sector, compared to women employed in the private sector. In Table A3 in the Supplemental Material, we show the regression output from all heterogeneity regressions, we implemented based on pre-birth characteristics. We only find heterogeneous responses with respect to the sector in which each household member was employed the year before birth of the first child.

\subsection{Mechanisms}

We find in Tables A4 and A5 in the Supplemental Material that women's labor income increases significantly while the men's labor income drops (yet insignificantly). We also find that both household members increase their parental leave take-up but men by a much higher factor. We estimate no significant effects on the propensity to being selfemployed and no significant effects on the unemployment rate. Finally, we estimate a 
small yet statistically significant reduction in the number of children. ${ }^{12}$

\section{References}

Avdic, D. And A. Karimi (2018): "Modern Family? Paternity Leave and Marital Stability," American Economic Journal: Applied Economics, 10(4), 283-307.

Browning, M., F. Bourguignon, P.-A. Chiappori and V. Lechene (1994): "Income and outcomes: a structural model of intrahousehold allocation," Journal of Political Economy, 102(6), 1067-1096.

Duvander, A.-Z., T. LAppegÅRd And G. Andersson (2010): "Family policy and fertility: fathers' and mothers' use of parental leave and continued childbearing inNorway and Sweden.," Journal of European Social Policy, 20(1), 45-57.

Ekberg, J., R. Eriksson and G. Friebel (2013): "Parental leave - A policy evaluation of the Swedish "Daddy-Month" reform," Journal of Public Economics, 97, 131 143 .

FARre, L. And L. Gonzalez (2017): "The effect of parental leave on fertility and labor market outcome," Working paper 978, Barcelona GSE Working paper series.

Kleven, H. J., C. Landais and J. E. SøgaARd (forthcoming): "Children and gender inequality: Evidence from Denmark," American Economic Journal: Applied Economics.

TAMm, M. (2018): "Father's leave-taking, childcare involvement and mother's labor market participation," IZA working paper 11873, IZA.

\footnotetext{
${ }^{12}$ We find that the number of years women are registered together with the birth partner decreases slightly from 6.74 years to 6.71 in our sample if the firstborn child is born after the reform. We also investigated how the reform changed the propensity to divorce. To investigate how the reform changed the propensity to divorce, we ran the regression in equation (1) on an extended sample with a binary indicator for being divorced as the left hand side variable. We find a small insignificant increase in the propensity to divorce potentially explaining the small reduction in fertility.
} 